\title{
VIOLAÇÃO DOS DIREITOS HUMANOS VIA DISCRIMINAÇÃO: UM PANORAMA DA VIOLÊNCIA PELO VIÉS DA INTERSECCIONALIDADE
}

\author{
Vladimir Pinto Coelho Feijó ${ }^{224}$ \\ Daniel Santos de Castro Gomes 225
}

Recebido em: 20/07/2018

Aprovado em: 02/10/2018

\begin{abstract}
RESUMO
O presente trabalho apresenta, de forma suscita, o cenário de violência experimenta por minorias sexuais. Expõe-se, de modo reflexivo, as relações de poder e subalternização experimentadas por minorias sexuais por meio de uma ótica interseccional, demonstrando como outros marcadores sociais de marginalização - não só o de cunho sexual e de gênero - pode interferir nessas relações de poder e no grau de violência vivenciado pelos indivíduos. Além disso, o artigo reflete acerca das legislações e dos mecanismos jurídicos que deveriam promover proteção a esse grupo, mas que não são aplicados na realidade fática das pessoas, seja por escolhas políticas, seja por não conseguirem atingir os indivíduos em decorrência do seu caráter homogeneizante. $\mathrm{O}$ artigo conclui argumentando como uma leitura interseccional pode ser benéfica em expor de forma mais profunda as relações de dominação.
\end{abstract}

Palavras-chave: Interseccionalidade. Violência sexual e de gênero. Direitos Humanos. Marcadores sociais.

\section{INTRODUÇÃo}

O Brasil, na perspectiva mundial, é classificado com parte do grupo de países que preveem certos direitos à comunidade LGBT. O país começa sua vida independente, mas manteve incorporada as Ordenações Filipinas ao seu ordenamento jurídico com duras punições à prática homossexual. "Toda pessoa, de qualquer qualidade que seja, que pecado de

\footnotetext{
${ }^{224}$ Doutorando em Direito Internacional pela Pontifícia Universidade Católica de Minas Gerais - PUC/MG. Mestre em Direito Público pela Universidade Federal de Minas Gerais. Professor universitário na Faculdade IBMEC/MG.

${ }^{225}$ Graduado em Direito pela Universidade Federal de Ouro Preto.
} 
sodomia por qualquer maneira cometer, seja queimado e feito por fogo em pó, para que nunca de seu corpo e sepultura possa haver memória, e todos os seus bens sejam confiscados para a Coroa de nossos Reinos [...]" (LARA, 1999, p.71).

Em seu trabalho sobre discriminação por orientação sexual no direito brasileiro o pesquisador Roger Rios (2016) enfatiza que não durou muito a previsão legal acima. Houve a descriminalização da sodomia com o advento do Código Criminal do Império em 1830. A homossexualidade ainda é objeto de intenso preconceito, discriminação e violência na sociedade brasileira. Os dados estatísticos disponíveis dão conta de que, apenas no Brasil, a cada três dias uma pessoa é assassinada em virtude de ódio motivado na orientação sexual (RIOS, 2016, p.384).

É importante lembrar que os poucos direitos reconhecidos expressamente na legislação à comunidade LGBT ainda não foram estabelecidos na Constituição ${ }^{226}$ de forma expressa. Importante frisar também que, apesar de implementados aos poucos, não têm sido aplicados de forma homogênea no país. Apesar disso, dados de organizações revelam o nível de violência contra o grupo em âmbito nacional. Como o Brasil não tem leis específicas que combatem a homofobia, esse tipo de violência é registrado em outros tipos de crimes, como discriminação, injúria ou agressão, por exemplo. Não há dados oficiais sobre a violência contra a comunidade LGBT no Brasil. Reconhece-se, porém, esforços esporádicos de publicizar dados sobre o tema. O Ministério de Direitos Humanos chegou a publicar, nos anos de 2011, 2012 e 2013, sob o título "Relatório sobre Violência Homofóbica no Brasil”, os dados estatísticos dos casos relatados. (BRASIL, 201[3]). Mas diferentes associações ligadas ao tema realizam levantamentos próprios e, com eles, pode-se ter ajuda para mensurar a violência cometida em âmbito nacional.

Sob a ótica jurídica, a organização The International Lesbian, Gay, Bisexual, Trans and Intersex Association (ILGA) destacou em seu relatório de 2017 sobre a Homofobia promovida pelo estaco que

\footnotetext{
${ }^{226}$ Merece atenção a existência da Proposta de Emenda à Constituição n ${ }^{\circ}$ 67, de 1999, de autoria do Deputado Federal Marcos Rolim, que apesar de ter recebido parecer positivo na CCJR em 13 de junho de 2001, foi arquivado pela Mesa Diretora da Câmara dos Deputados em 31 de janeiro de 2003. Essa PEC propôs a alteração do artigo $3^{\circ}$, inciso IV, e do artigo $7^{\circ}$, inciso XXX, da Constituição de 1988 . Tais dispositivos teriam a seguinte redação: "Art. $3^{\circ}$, IV - promover o bem de todos, sem preconceito de origem, raça, sexo, orientação sexual, crença religiosa, cor, idade e quaisquer outras formas negativas, de discriminação."; art. $7^{\circ}$, XXX - proibição de diferença de salários, de exercício de funções e de critério de admissão por motivo de sexo, orientação sexual, crença religiosa, idade, cor ou estado civil.”. Dentre as justificativas da Proposta de Emenda à Constituição se fez juntar a apresentação de anteriores projetos no mesmo sentido, tanto na Assembléia Constituinte de 1987, quanto projeto durante a revisão constitucional de 1993 e uma outra submetida no ano de 1995. Dados disponíveis em: < http://www.camara.gov.br/proposicoesWeb/fichadetramitacao?idProposicao=14330>. Acesso em 17 de maio de 2018.
} 


\begin{abstract}
A Constituição do Brasil não contém uma proibição explícita da discriminação com base na orientação sexual. No entanto, várias jurisdições dentro do país o fazem. Entre elas estão as Constituições dos Estados de Alagoas (Art. 2.1; 2001), Distrito Federal (Art. 2.5; 1993), Mato Grosso (Art. 10.3; 1989), Pará (Art. 3.4; 2007), Santa Catarina (Art. (2002) e Sergipe (Art. 3.2; 1989) ${ }^{227}$. (CARROLL, MENDOS, 2017, p.47, tradução livre)
\end{abstract}

O documento, porém, destaca também haver sincero compromisso de combate a discriminação via estabelecimento de normas protetivas.

\begin{abstract}
Não há dispositivos legais federais que agravam penalidades por crimes motivados pela orientação sexual da vítima no Brasil, embora cerca de $78 \%$ da população viva em jurisdições onde as leis locais especificam tal proteção. Alguns estados promulgaram leis locais que impõem penalidades - como multas e revogação de licenças - a atos de violência e / ou atos de discriminação com base na orientação sexual. Estes incluem: Amazonas (2006); Bahía (1997), Distrito Federal (2000); Espírito Santo (2014); Maranhão (2006); Mato Grosso do Sul (2005); Minas Gerais (2002); Pará (2011); Paraíba (2003); Piauí (2004); Rio de Janeiro (2015); Rio Grande do Norte (2007); Rio Grande do Sul (2002); Santa Catarina (2003); São Paulo (2001); além de cidades como Fortaleza (Ceará) e Recife (Pernambuco) ${ }^{228}$. (CARROLL, MENDOS, 2017, p.60, tradução livre)
\end{abstract}

Esse quadro de violência e violações de direitos demonstra uma necessidade do Estado intervir de alguma forma, seja por meio de mecanismos jurídicos (legislações) ou por políticas públicas com o objetivo de proteger a comunidade LGBT, e promover direitos para essas pessoas.

\title{
2 DIREITO DE PROTEÇÃO
}

Os valores dos Direitos Humanos são os direitos inerentes a todo ser humano, oponíveis a todos, inclusive ao Estado. Eles existem com o objetivo de garantir uma existência minimamente digna às pessoas naturais. Para assegurar a dignidade, ao Estado,

\footnotetext{
227 The Constitution of Brazil does not contain an explicit prohibition of discrimination based on sexual orientation. However, several jurisdictions within the country do. These include the Constitutions of the States of Alagoas (Art. 2.1; 2001), Federal District (Art. 2.5; 1993), Mato Grosso (Art. 10.3;1989), Pará (Art. 3.4; 2007), Santa Catarina (Art. 4.4; 2002) and Sergipe (Art. 3.2; 1989). (CARROLL, MENDOS, 2017, p.47)

${ }^{228}$ There are no federal provisions aggravating penalties for crimes motivated by the victim's sexual orientation in Brazil, although around $78 \%$ of the population live in jurisdictions where local laws specify such protection. Some states have enacted local laws that impose penalties — such as fnes and revocation of licences- to acts of violence and/or acts of discrimination based on sexual orientation. These include: Amazonas (2006); Bahía (1997), Distrito Federal (2000); Espírito Santo (2014); Maranhão (2006); Mato Grosso do Sul (2005); Minas Gerais (2002); Pará (2011); Paraiba (2003); Piauí (2004); Rio de Janeiro (2015); Rio Grande do Norte (2007); Rio Grande do Sul (2002); Santa Catarina (2003); São Paulo (2001); as well as cities such as Fortaleza (Ceará) and Recife (Pernambuco). (CARROLL, MENDOS, 2017, p.60)
} 
incumbe o dever de proteção, punindo qualquer violação a eles. Desse modo, assim aponta Paulo Roberto Vecchiatti

[...] fica evidente que a população GLBTT (Gays, Lésbicas, Bissexuais, Transexuais e Travestis) precisa de proteção do Estado, tendo em vista o preconceito social contra ela existente. $\mathrm{O}$ aspecto material do princípio da igualdade, que determina a necessidade de se tratar desigualmente os desiguais, é o fundamento jurídico legitimador de leis que visem a proteção da população GLBTT, tendo em vista que ela se configura como grupo estigmatizado alvo de inúmeros preconceitos sociais (gays sofrem preconceito por orientação sexual; héteros não o sofrem - assim, são desiguais nesse ponto específico, sendo portanto válido tratamento diferenciado, protegendo aqueles). (VECCHIATTI, 2008, p.2)

Diante do cenário de violência contra a comunidade LGBT no Brasil, podemos perceber que o Estado não está comprometido com os princípios e garantias, insculpidos no texto da Constituição de 1988 e em documentos internacionais de Direitos Humanos recepcionados pelo Brasil. Nesse sentido, assim ponderam Bahia e Silva:

[...] há um número elevado de casos de violência homofóbica e transfóbica (homotransfóbica) no Brasil, o que pode ser visto tanto a partir de dados oficiais quanto da comparação destes com denúncias de outros casos não reportados, inclusive porque a violência de natureza homotransfóbica possui traços característicos.[...] Tal constatação viola a Constituição de 1988, justamente aquela chamada de "cidadã" e que tantos avanços vem proporcionando para o constitucionalismo e para a democracia brasileira; violam-se, e.g., o direito à nãodiscriminação, que é um objetivo fundamental da República (art. $3^{\circ}$, IV) e o direito de igualdade (art. $5^{\circ}$, caput) - compreendida esta não apenas como isonomia mas também como direito à diversidade11. Complementarmente, há vários documentos internacionais (os quais o Brasil recepcionou) prevendo, explícita ou implicitamente, a necessidade de os países preverem mecanismos específicos que possibilitem a prevenção e a adequada repressão à homofobia. (BAHIA; SILVA, 2015, p.184)

O primeiro valor a impedir juridicamente a tolerância às violências e discriminações é o princípio da igualdade. A dificuldade da natureza principiológica do direito de igualdade, chama à importância da necessidade de concretização deste princípio diante as diversas situações fáticas e jurídicas. "Isto significa que o intérprete tem que compreender o conteúdo desta norma de direito fundamental situado no contexto histórico concreto, sem ignorar a realidade dos fatos e o estágio de conhecimento atinente à realidade problematizada juridicamente" (RIOS, 2016, p. 386).

Além de levar em consideração os valores constitucionalmente prescritos, é importante destacar que o Brasil se comprometeu com diversos documentos internacionais que visam promover direitos e proteção para as pessoas que se identificam como LGBTs, um desses documentos é a Resolução n²435: Direitos Humanos, Orientação Sexual e Identidade de Gênero que demonstra preocupação com atos de violência contra a população LBGT e 
garante textualmente medidas de proteção para essas pessoas. Desse modo, esclarece Alexandre Bahia

\begin{abstract}
No que tange a Tratados Internacionais (e similares) sobre Direitos Humanos de que o Brasil é signatário e que, de alguma forma, tratam da igualdade (bem como da proibição de discriminação), podemos citar a Convenção Internacional sobre a Eliminação de todas as formas de Discriminação Racial (1965): “Considerando que todas as pessoas são iguais perante a lei e têm direito a igual proteção contra qualquer discriminação e contra qualquer incitamento à discriminação" e seu Art. $1^{\text {o }}$. “(...) a expressão 'discriminação racial' significará qualquer distinção, exclusão, restrição ou preferência baseada em raça, cor, descendência ou origem nacional ou étnica que tem por objetivo ou efeito anular ou restringir o reconhecimento, gozo ou exercício num mesmo pleno (em igualdade de condição), de direitos humanos e liberdades fundamentais no domínio político, econômico, social cultural ou em qualquer outro domínio de sua vida”. A Resolução n. 2435: Direitos Humanos, Orientação Sexual e Identidade de Gênero, aprovada pela Assembleia Geral da OEA em 03 de junho de 2008, mostrando preocupação com os "atos de violência e das violações aos direitos humanos correlatas perpetradas contra indivíduos, motivados pela orientação sexual e pela identidade de gênero". Em 2008 foi aprovada por 66 países (incluindo o Brasil) uma Declaração da ONU condenando violações dos direitos humanos com base na orientação sexual e na identidade de gênero (A/63/635, de 22/12/08). Nessa Declaração os países signatários reafirmaram a vigência do princípio da não discriminação, que exige que os direitos humanos se apliquem por igual a todos os seres humanos, independentemente de sua orientação sexual ou identidade de gênero. (BAHIA, 2012, p.1)
\end{abstract}

No Brasil na contra mão da comunidade internacional comprometida com os Direitos Humanos e com a proteção de minorias, não existe uma legislação específica para tipificar crimes de violação de direitos e punir indivíduos que cometem crimes de natureza homofóbica ${ }^{229}$. Entendemos que há uma ausência ou/e ineficiência de políticas públicas de proteção à comunidade LGBT (tendo em vista o acentuado quadro de violência). Esse panorama demonstra um total descumprimento do Estado com os princípios constitucionais e com compromissos de proteção de minorias assentados em documentos internacionais. Nesse sentido, elucidam Bahia e Silva

A Constituição de 1988 criou um sistema de direitos e garantias que exige que o Estado Brasileiro aja para coibir a violência homofóbica. De igual forma, há documentos sobre Direitos Humanos oriundos de organismos internacionais (como Organização das Nações Unidas - ONU e Organização dos Estados Americanos OEA) e recepcionados pelo Brasil (e que integram nosso sistema de Direitos Fundamentais, art. $5^{\circ}, \S \S 2^{\circ}$ e $3^{\circ}$ - Constituição de 1988) que impõem ao nosso País o dever objetivo de criar mecanismos legais de políticas específicas para prevenir e punir a violência de natureza homofóbica. Dever este que o Brasil tem sistematicamente se recusado a cumprir. (BAHIA; SILVA, 2015, p.185)

229 Atualmente tramita no Senado uma Sugestão Popular (SUG 05/2016) que propõe a criminalização da discriminação por orientação sexual e identidade de gênero, equiparado ao crime de racismo. O PLC 122/06 que tinha por objetivo colocar a homofobia no rol de crimes da Lei 7.716 de 1989, encontra-se arquivado. 
$\mathrm{Na}$ legislação federal há registro à proibição de discriminação por "preferência sexual", além de incluir, dentre as proibições de discriminação, a situação dos homossexuais. É possível que a pressão internacional haja surtido efeito. Em conferência internacional firmaram-se os Direitos Civis o Políticos de todas as pessoas devendo eles ser, na sequência, incorporados à legislação nacional.

[...]não se pode esquecer a pertinência dos tratados internacionais de direitos humanos incorporados ao nosso ordenamento jurídico. De fato, pela aplicação da Convenção Internacional dos Direitos Civis e Políticos de 1966, o Comitê de Direitos Humanos das Nações Unidas considerou indevida a discriminação por orientação sexual no tocante à criminalização de atos sexuais homossexuais, ao examinar o caso Toonen v. Australia. (RIOS, 2016, p. 401)

O Direito, entretanto, fixa o dever ser. A realidade social não se transforma magicamente. De forma triste sabemos que a transformação pode ser lenta. A investigação da complexidade da violência e a formulação de respostas jurídicas com a intenção de coibir violações de direitos devem ter como ponta pé o estudo e a compreensão da realidade fática dos indivíduos sob a ótica da interseccionalidade ${ }^{230}$. A estes, podem incidir muitos fatores de discriminação.

\section{A INTERSECCIONALIDADE}

É preciso compreender que a discriminação não ocorre de forma simplificada, existem diversos marcadores sociais que tornam alguns indivíduos mais vulneráveis à violência e à exclusão social. Portanto, compreender e investigar esse processo complexo de violência e as formas múltiplas de discriminação é fator fundamental para formulação de respostas jurídicas eficazes para o combate de violações de direitos e crimes de natureza homofóbica. Dessa forma, explica Marcia Macêdo que

A discriminação é um fenômeno múltiplo e complexo. Os diferentes contextos, redes relacionais, fatores intercorrentes e motivações que desencadeiam a discriminação não são redutíveis a um ou outro critério isolado. Não basta reprovar a discriminação racial e a discriminação sexual, pois a injustiça sofrida por mulheres brancas é diversa daquela vivida por mulheres negras, assim como a discriminação

\footnotetext{
${ }^{230}$ Uma conceituação do problema que busca capturar as consequências estruturais e dinâmicas da interação entre dois ou mais eixos da subordinação. Ela [interseccionalidade] trata especificamente da forma pela qual o racismo, o patriarcalismo, a opressão de classe e outros sistemas discriminatórios criam desigualdades básicas que estruturam as posições relativas de mulheres, raças, etnias, classes e outras (CRENSHAW, 2002, p. 177)
} 
experimentada por homens negros e por mulheres negras não é a mesma. (MACÊDO, 2008, p.12)

Um exemplo positivo que demonstra a capacidade eficiente de investigação das relações de dominação pelo viés da inteseccionalidade mostra-se pela denominada interseccionaliade emacipadora ${ }^{231}$. Fora constado que a gênese dos sindicatos profissionais das pessoas que se dedicam ao trabalho doméstico remunerado no país, ocorrera pelo diálogo entre os movimentos feminista e negro (visto que a maioria das pessoas que se dedicam ao trabalho doméstico remunerado no Brasil apresentam os marcadores mulher/negra). Nesse sentido, os sindicatos por meio de alianças entre os movimentos negro, feminista e classista; vem conquistando direitos e espaço para as pessoas que se dedicam ao trabalho doméstico.

Trata-se da luta pelo reconhecimento da igualdade.

[...] sem que seja vencida tal realidade discriminatória, cidadãos continuarão a ver negligenciados direitos e garantias constitucionais fundamentais, em virtude de preconceito e intolerância. Atitudes fundadas nestas bases não podem subsistir, uma vez que tamanha violência ao princípio isonômico compromete, a um só tempo, a dignidade da pessoa humana e os meios processuais para sua proteção. Impende, portanto, afirmar-se a operatividade do princípio da igualdade diante de diferenciações injustificadas, fundadas na orientação sexual dos sujeitos das relações jurídicas processuais. (RIOS, 2017, p.404)

Nesse sentido, é oportuno nos questionarmos se alguns membros da comunidade LGBT que apresentam outros marcadores sociais estão mais vulneráveis aos atos de violência de caráter homofóbico? Para responder esse questionamento entendemos que o estudo da violência sob o olhar da interseccionalidade consegue expor nesse emaranhado social os outros marcadores que muitas das vezes são invisíveis, mas que geram nos indivíduos vulnerabilidade e subordinação social.

A inserção da pessoa na sociedade, em especial aquelas com marcadores de discriminação, precisa romper com a tradição. Ao descrever a luta feminista através da revolucionária obra de Gloria Anzaldúa, Claudia Costa e Eliana Ávila (2005) destacaram as múltiplas identidades da escritora que, além de mulher, possuía origem latina e também negra, dificultando seu acesso em nível de igualdade às demais.

$231 \mathrm{Na}$ formação dos sindicatos das trabalhadoras domésticas como movimento decolonial, observa-se um frutífero diálogo e articulação com movimentos sindicais, feministas e negros, que denominamos de interseccionalidade emancipadora. Em outras palavras, nem sempre raça, classe e gênero estarão associados à opressão e à desigualdade, em algumas situações raça, classe e gênero podem ser mobilizadas Revista Sociedade e Estado -para o estabelecimento de solidariedade política em torno de projetos decoloniais. Muitas vezes, e dependendo do contexto histórico, as categorias sociais de diferenciação que fundamentam a noção de interseccionalidade podem resultar em formas democráticas de agência política. (COSTA, 2015, p.154) 
Enfatizando que os terrenos da diferença são mais que nunca espaços de poder, a autora complica radicalmente o discurso feminista da diferença. Migrando pelos entre-lugares da diferença, mostra como esta é constituída na história e adquire forma a partir de articulações sempre locais - suas mestiçagens múltiplas revelam simultaneamente mecanismos de sujeição e ocasiões para o exercício da liberdade. (COSTA; ÁVILA, 2005, p.694)

Num jogo de participação que lida com pressões por assimilação cultural ao mesmo tempo em que indivíduos combativos tentam ser cooptados para evitar a formação de um movimento que tente quebrar com a tradição. Essas pressões são difusas. As ações mais perceptíveis, entretanto, são as violências contra os discriminados.

\section{UM PANORAMA DA VIOLÊNCIA}

Existe no Brasil uma cultura de agressão e violação de direitos contra o "diferente". Podemos perceber como são tratadas em nossa sociedade de forma desumana, subalterna e negativamente desigual as pessoas que apresentam alguma característica "não convencional", como minorias étnicas, minorias sexuais, pessoas de baixo status econômico, dentre outros.

Um estudo intitulado Sentindo na Pele: Percepções de Discriminação Cotidiana de Pretos e Pardos no Brasil chama atenção, quanto a problemática da discriminação no tocante a raça, para inclusive a percepção de preconceito, afirmando que "[...] temos uma situação paradoxal: os pardos estão extremamente próximos dos pretos no que toca à desigualdade de oportunidades e de resultados e ao mesmo tempo longe destes quanto à percepção do preconceito e da discriminação" (DAFLON, CARVALHAES, FERES Jr., 2017, p.294). No presente trabalho não queremos explorar toda a complexidade, mas vale pontuar como o tema é intrincado. Pode-se citar dados do Mapa da Violência 2017, editado pelo IPEA, indicando como o preconceito produz efeitos visíveis. “Ao calcular a probabilidade de cada cidadão sofrer homicídio, os autores concluíram que os negros respondem por 78,9\% dos indivíduos pertencentes ao grupo dos 10\% com mais chances de serem vítimas fatais" (CERQUEIRA et al, 2017, p.30). Quando incluímos o fator gênero o caso fica ainda mais dispare. Entre os anos de 2005 e 2015 o número médio de homicídio de mulheres subiu 18,9\% no país, porém, enquanto houve uma elevação na taxa de homicídio de mulheres negras se elevou em $22 \%$ entre o homicídio de mulheres não negras houve uma redução de 7,4\% (CERQUEIRA et al, 2017, p.39-41).

$\mathrm{Na}$ sequência, o foco será na discriminação e violência por orientação sexual ou identificação de gênero. Para a compreensão dessa lógica de exclusão e violência se faz 
necessário uma percepção que não coloque em posição universal e homogeneizante os indivíduos da comunidade LGBT. É preciso entender que existem indivíduos dentro da comunidade que sofrem mais violência e estão mais vulneráveis a ela. O presente trabalho de pesquisa com auxílio de conceitos da interseccionalidade e do direito antidiscriminatório tenta entender esse quadro de violência que se apresenta de forma complexa e heterogênea.

A percepção pela ótica interseccional com auxilio de conceitos do direito antidiscriminatório é fundamental para compreensão de uma realidade de subordinação e exclusão social bastante complexa e heterogênea. A título de exemplificação ocorre por entendermos que a violência de cunho homofóbica que um indivíduo gay, negro, pobre e morador da periferia de um grande centro urbano, é diferente da violência experimentada por um indivíduo gay, branco e de classe média, uma vez que o primeiro indivíduo além de sofrer violações por ser homossexual, sofre também outras formas de discriminação por ser negro e pela sua condição social.

Dessa forma, entendemos que é necessária uma análise mais profunda dos processos de violações e violência em que a comunidade LGBT está submetida. Uma percepção interseccional pode expor outros fatores de discriminação que alguns membros da comunidade LGBT sofrem, permitindo a elaboração de respostas jurídicas e de políticas públicas com o objetivo de combater a homofobia, fazendo valer os princípios constitucionais e compromissos que o Brasil se comprometeu internacionalmente em relação à garantia de direitos para a comunidade LGBT. A visibilidade das situações discriminatórias não percebidas abre a possibilidade de visibilidade dos indivíduos e grupos até então ignorados e, com isso, quem sabe, ampliando as chances de sucesso das políticas públicas contra a discriminação (DORLIN, 2012, p. 10). Apesar de não concordar, não se pode esconder as críticas, dentre as mais contundentes a apresentada por Danièle Kergoat, defendendo que a multiplicidade de pontos de entrada (casta, religião, região, etnia, nação etc., e não apenas raça, gênero, classe) leva a um perigo de fragmentação das práticas sociais e à dissolução da violência das relações sociais, com o risco de contribuir à sua reprodução (KERGOAT, 2012, pp. 21-22).

É necessário entender a complexidade da violência de caráter homofóbica e perceber que ela não ocorre de forma homogênea e universal. As violações de direitos ocorrem com mais frequência e maior agressividade contra populações que apresentam outros marcadores sociais de exclusão, como nível de renda, escolaridade e raça. Prova disso, é o que atestam os dados da Secretaria de Direitos Humanos que apontam que a maioria dos casos de violações 
de direitos contra a população LGBT ocorridos em 2012 se deram em indivíduos pretos e pardos totalizando 39,9\% das vítimas ${ }^{232}$. Nesse sentido, esclarece Moreira:

\begin{abstract}
As pessoas possuem uma multiplicidade de identidades e isso significa que elas podem estar expostas a diversos processos discriminatórios. Essas formas de estratificação não operam de forma isolada; elas atuam simultaneamente para promover a exclusão de minorias em diversos níveis e em diferentes situações. A ação concomitante do racismo e da homofobia cria uma minoria dentro de uma minoria, o que torna a opção por ações generalistas insatisfatória. Mais do que isso, essa realidade mostra que uma noção de justiça compreendida como tratamento simétrico também não conseguirá promover a inclusão porque ela não apresenta elementos suficientes para tratar a situação única de pessoas que são excluídas em função de uma interseção de discriminações. (MOREIRA, 2016, p.10).
\end{abstract}

A compreensão da lógica de violência com o auxílio da interseccionalidade nos faz refletir de forma mais profunda uma relação de poder e subordinação, o que pode ser um caminho mais eficiente para encontrarmos respostas jurídicas com o objetivo de combater essa lógica de dominação, violência e exclusão social. "Com a interseccionalidade, se possibilita a compreensão das relações de poder e de como se dá o seu real funcionamento, muito além da enumeração formal de critérios proibidos de discriminação e de uma percepção matemática dos fatores discriminatórios. "(DORLIN, 2012, p.10).

As consequências da discriminação logo na adolescência podem contribuir para um panorama de ampliada segregação, exclusão do mercado de trabalho e em quadro pior de saúde. O ciclo negativo é auto evidente. Qualquer tipo de agressão vivenciada na adolescência dentro do ambiente escolar é motivo para a percepção da vítima como uma excluída dentro desse ambiente. Seja por agressões de ordem física ou verbal, os casos de abandonando dos estudos são muitos. Quando a pessoa envolvida não se encaixa nos padrões heteronormativos as agressões são ainda mais incisivas justamente por essa condição de estar fora dos padrões. Cria-se um panorama de insegurança aumentada, mais e mais, passando a pessoa do pertencimento para a exclusão. Um estudo realizado pela ABGLT (Secretaria de Educação Associação Brasileira de Lésbicas, Gays, Bissexuais, Travestis e Transexuais) emitiu os seguintes dados resumo

Os/as estudantes tinham duas vezes mais probabilidade de ter faltado à escola no último mês se sofreram níveis mais elevados de agressão relacionada à sua

\footnotetext{
232 Outro dado importante na caracterização sociodemográfica da população LGBT é a raça/cor autodeclarada. Como informa o gráfico a seguir, pretos e pardos totalizam 39,9\% das vítimas; seguidos por brancos, com 27,5\%; amarelos e indígenas, somados com 0,6\%. Não informados totalizam $32 \%$ das vítimas. Proporcionalmente, os números correspondem aos de 2012, quando a população preta e parda somou 40,55\% das vítimas nos dados do poder público, também seguida pela branca $(26,84 \%)$. Estes dados acompanham estudos mais amplos sobre violência no Brasil, que apontam a população de pretos e pardos, como a mais vitimizada pela violência. Dados disponíveis em: <http://www.mdh.gov.br/assuntos/lgbt/pdf/relatorio-violenciahomofobica-ano-2012>. Acesso em: 17 maio 2018.
} 
orientação sexual $(58,9 \%$ comparados com $23,7 \%$ entre os/as que sofreram menos agressão) ou expressão de gênero (51,9\% comparados com 25,5\%). [...]. Os/as estudantes LGBT que vivenciaram níveis mais elevados de agressão verbal por causa da orientação sexual ou expressão de gênero (frequentemente ou quase sempre) tinham 1,5 vezes mais probabilidade de relatar níveis mais elevados de depressão (73,7\% comparados com 43,6\% [que sofreram menos agressão] no caso da orientação sexual; $67,0 \%$ comparados com $45,3 \%$ no caso da identidade/expressão de gênero), [...] (ABGLT, 2016, p. 19).

Soma-se ao fato o relato de apenas $26,4 \%$ dos alunos terem algum tema LGBT ensinado em pelo menos uma das disciplinas cursadas (ABGLT, 2016, p.59). O ciclo perverso insere o público LGBT em outras estatísticas. Quando um jovem se rebela ou é expulso da escola por não se enquadrar nos padrões, como se todos fossem um produto em linha de produção fabril), reduzem-se as chances de aderência e concordância aos valores sociais vigentes. O indivíduo se excluir, sobram incentivos para trajetória de delinquência e crime (CERQUEIRA et al, 2017, p.26). Se além de LGBT ele pertence ao grupo dos negros soma os riscos desses. "Ao calcular a probabilidade de cada cidadão sofrer homicídio [...] os negros respondem por 78,9\% dos indivíduos pertencentes ao grupo dos $10 \%$ com mais chances de serem vítimas fatais" (CERQUEIRA et al, 2017, p.30).

Aos que vencem as violências do ensino básico e ingressam no ensino superior os desafios permanecem. Se consideramos o ambiente universitário um lugar de socialização e formação cidadã, imaginaríamos um espaço acolhedor e dedicado a formação de valores e projetos inclusivos. Entretanto, os desafios são imensos. Pode-se dizer que

[...] os atuais desafios enfrentados pelos estudantes LGBT, estão atrelados às questões financeiras, assistência estudantil desfavorável, e sentimento de rejeição e exclusão por atos preconceituosos. Nesse sentido, a condição de ser LGBT, reforça essas dificuldades, tornandoas mais evidentes, fazendo com que a permanência se configure como um verdadeiro ato de resistência. Todavia, de modo geral, os estudantes vêm superando os desafios de permanecer na universidade, e atrelam isso à forte identificação pelo o curso (SANTOS, 2017).

Aos que abandonam os estudos, as estatísticas identificadas os colocam escondidos entre o restante da sociedade. Mas, se o "[...] perfil típico das vítimas fatais permanece o mesmo: homens, jovens, negros e com baixa escolaridade" (CERQUEIRA et al, 2017, p.50), as preocupações não podem excluir aquelas com os que sobrevivem a nesse cenário perverso, mas ainda se submetem a outras formas de violência. Vejamos o caso do mercado de trabalho em que algumas "táticas de sobrevivência" já foram relatadas. Helio Irigary e Maria Freitas (2013, p.84) publicaram as táticas dividias por categorias de LGBT, no público gay masculino sendo os totalmente assumidos adeptos das estratégias de "gladiadores" ou "pacificadores"; 
enquanto os parcialmente assumidos optam por ser "gente boa" ou "super homens", enquanto finalmente, os não-assumidos se dividem entre os "machões", "sedutores" ou "invisíveis". Independente da sobrevivência a situação de violência é uma constante, vejamos

\begin{abstract}
A grande maioria dos entrevistados revelou-se homo e bissexuais parcialmente assumidos. Estes podem ser heterossexuais organizacionais, aqueles que apesar de serem assumidos perante a família e os amigos, hesita em se assumir no ambiente de trabalho; ou heterossexuais funcionais, indivíduos que compartilham sua identidade sexual apenas com um seleto grupo de amigos e a omite a qualquer preço da família e dos colegas de trabalho. Na maioria das vezes, os indivíduos que compõem esta categoria vivem uma vida dupla fictícia, ou seja, inventam namoradas [...]

Os discursos dos indivíduos totalmente assumidos e parcialmente assumidos evidenciaram uma sensação de rejeição por parte da sociedade e indignação de só serem reconhecidos como cidadãos na hora de pagar os impostos e não terem seus direitos legais e previdenciários plenamente reconhecidos. (IRIGARAY; FREITAS, 2013 , p.83, grifos no original)
\end{abstract}

No ambiente de trabalho a violência aos LGBT também relata a interseccionalidade. No mesmo estudo, Irigaray e Freitas assinalam que vítimas e agressores se confundem em alguns momentos já que "Todos os entrevistados declararam já terem sido vítimas ou presenciado algum tipo de atitude discriminatória nas organizações que trabalham, mesmo por parte de colegas que pertencem a outras minorias (negros, deficientes, pobres), que também são alvo de discriminação (IRIGARAY; FREITAS, 2013, p.83).

\title{
5 CONSIDERAÇÕES FINAIS
}

É possível afirmar que os indivíduos mais vulneráveis à violência e às agressões de caráter homofóbico são pessoas que apresentam outros marcadores sociais que são historicamente subjugados e estereotipados, como minorias étnicas, pessoas de baixa renda e baixa escolaridade, pessoas com deficiência física, dentre outros. Nesse sentido, poderíamos assim constatar que existem grupos minoritários dentro da comunidade LGBT, que sofrem violências mais graves e perversas, mas que muitas das vezes são silenciados seja pelo enfretamento da questão da homofobia de forma generalizada e universalizante, seja pela falta de acesso aos mecanismos jurídicos que lhe dariam proteção e dignidade.

Portanto, é necessário entender que existem grupos que sentem e experimentam da violência de cunho homofóbica de forma mais acentuada e gravosa, por serem portadores de outros marcadores sociais que os condicionam a estarem sempre em uma posição de inferioridade. Desse modo, as políticas de combate à homofobia e garantia de direitos para a comunidade LGBT, muitas das vezes não são eficazes para proteger esses indivíduos, pois 
elas apresentam uma linguagem e toda uma estratégia universalizante que não conseguem atingir esses grupos. Por óbvio que não se propõe que as políticas de proteção aos cidadãos LGBTs sejam abolidas, elas foram responsáveis por diversos progressos na luta contra a homofobia em nossa sociedade. Entretanto, acredita-se que os mecanismos jurídicos de proteção poderiam ser reformulados e adaptados a uma realidade mais complexa, e que fossem mais sensíveis ao diverso dentro da própria comunidade minoritária, deixando praticas homogeneizantes.

Por fim, podemos concluir que existem grupos de pessoas dentro da comunidade LGBT que são mais vulneráveis aos atos de agressões de caráter homofóbico, por apresentarem outros marcadores sociais. Além disso, podemos entender que as políticas públicas e mecanismos jurídicos de proteção desses indivíduos podem não ser muito eficientes na proteção dessas pessoas por apresentarem uma abordagem universal que colocam os indivíduos em todo homogêneo, sem levar em consideração as peculiaridades e os estigmas sociais que alguns indivíduos enfrentam. Assim como disseram Costa e Ávila (2005, p.697), chega-se a visão comum de que a leitura interseccional impede a redução das subjetividades em categorias identitárias fixas e abre espaço para a construção de novas alianças ou redes de solidariedade.

\section{REFERÊNCIAS}

ABGLT. Relatório da Secretaria de Educação da Associação Brasileira de Lésbicas, Gays, Bissexuais, Travestis e Transexuais. Pesquisa nacional sobre o ambiente educacional no Brasil 2016: As Experiências de Adolescentes e Jovens LGBT em nossos Ambientes Educacionais. Disponível em: <http://static.congressoemfoco.uol.com.br/2016/08/IAEBrasil-Web-3-1.pdf> Acesso em 24 de maio de 2018.

BAHIA, Alexandre Gustavo Melo Franco; SILVA, Diogo Bacha (2015). Necessidade de criminalizar a homofobia no Brasil: porvir democrático e inclusão das minorias. Disponível em: $<$ https://www.researchgate.net/publication/282465145_NECESSIDADE_DE_CRIMINALIZ AR_A_HOMOFOBIA_NO_BRASIL_PORVIR_DEMOCRATICO_E_INCLUSAO_DAS_M INORIAS.>. Acesso em 05 de maio de 2018.

BAHIA, Alexandre Gustavo Melo Franco. (2012) Homofobia no Brasil, resoluções internacionais e Constituição de 1988. Disponível em: <https://jus.com.br/artigos/21999/homofobia-no-brasil-resolucoes-internacionais-e-aconstituicao-de-1988>. Acesso em de maio de 2018. 
BRASIL. Constituição Federal de 1988. Promulgada em 5 de outubro de 1988. Disponível em http://www.planalto.gov.br/ccivil_03/constituicao/constituição.htm>. Acesso em 05 de maio de 2018.

CARROLL, Aengus. MENDOS, Lucas Ramón. State-sponsored Homophobia: A World Survey of Sexual Orientation Laws, Criminalisation, Protection and Recognition. ILGA, 2017. Disponível em: <https://ilga.org/downloads/2017/ILGA_State_Sponsored_Homophobia_2017_WEB.pdf>. Acesso em 08 de maio de 2018.

CERQUEIRA, Daniel et al. Atlas da violência 2017. 2017. IPEA e FBSP. Disponível em: <http://www.ipea.gov.br/atlasviolencia/download/2/2017>. Acesso em 24 de maio de 2018.

COSTA, Joaze Bernardino. Descolonidade e interseccionalidade emancipadora: a organização política das trabalhadoras doméstica no Brasil. Revista Estado e Sociedade , v. 30, n.1, p.154-155, 2015.

COSTA, Claudia de Lima; ÁVILA, Eliana. Gloria Anzaldúa, mestiza consciousness, and" feminism of difference". Revista Estudos Feministas, v. 13, n. 3, p. 691-703, 2005.

CRENSHAW, Kimberle. Demarginalizing the intersection of race and sex: A Black feminist critique of antidiscrimination doctrine, feminist theory, and antiracist politics [1989]. In: Feminist legal theory. Routledge, 2018. p. 57-80.

DAFLON, Verônica; CARVALHAES, Flávio; FERRES Jr., João. Sentindo na Pele: percepções de discriminação cotidiana de pretos e pardos no Brasil. Revista Dados. 2017. Vol. 60 n². p.293-330. Disponível em: < http://www.scielo.br/pdf/dados/v60n2/0011-5258dados-60-2-0293.pdf>. Acesso em 24 de maio de 2018.

DORLIN, Elsa. Séxo, gênero y sexualidades. Introducción a la teoria feminista. Buenos Aires: Nueva Visión, 2009.

IRIGARAY, Helio Arthur; FREITAS, Maria Ester. Estratégia de sobrevivência dos gays no ambiente de trabalho. Revista Psicologia Política, v. 13, n. 26, p. 75-92, 2013.

KERGOAT, Danièle. Se battre, disent-elles. Paris, La Dispute (col. Le Genre du Monde). Lowy, Ilana. (2002), "Universalité de la science et connaissances situées”. In: Gardey, D. \& Lowy, I. (orgs.). Les sciences et la fabrication du masculin et du féminin. Paris, Ed. des Archives Contemporaines, 2012. 
LARA, Silvia Hunold. Ordenações filipinas: livro V. Editora Companhia das Letras, 1999.

MACÊDO, Márcia dos Santos. Na trama das interseccionalidades: mulheres chefes de família em Salvador. 2008. Pós-graduação em Ciências Sociais, Faculdade de Filosofia e Ciências Humanas da Universidade Federal da Bahia (UFBA). Dissertação de Mestrado. Disponível $<$ https://repositorio.ufba.br/ri/bitstream/ri/10983/1/Dissertacao\%20Marcia\%20Macedoseg.pdf $>$. Acesso em 03 de maio de 2018.

MOREIRA, Adilson José. Direitos fundamentais como estratégias anti-hegemônicas: um estudo sobre a multidimensionalidade de opressões. Revista Quaestio Iuris, v. 09, $\mathrm{n}^{\mathbf{o}} 03$, Rio de Janeiro, 2016.

RIOS, Roger Raupp. A homossexualidade e a discriminação por orientação sexual no direito brasileiro. Direito e Democracia, v. 2, n. 2, 2016.

RIOS, Roger Raupp; SILVA, Rodrigo (2015). Discriminação Múltipla e Discriminação Interseccional: aportes do feminismo negro e do direito da antidiscriminação. Disponível em: < http://www.scielo.br/pdf/rbcpol/n16/0103-3352-rbcpol-16-00011.pdf>. Acesso em 04 de novembro de 2017

SANTOS, Jaílson Batista dos. A condição de ser LGBT e a permanência na universidade: um estudo de caso no Curso de Pedagogia - Educação do Campo. COIPESU $4^{\circ}$ Colóquio Internacional em Educação Superior. UFPB. 04 a 06 de setembro de 2017. Disponível em: <http://www.coipesu.com.br/upload/trabalhos/2017/18/a-condicao-de-ser-lgbt-e-apermanencia-na-universidade-um-estudo-de-caso-no-curso-de-pedagogia-educacao-docampo.pdf>. Acesso em 25 de maio de 2018.

VECCHIATTI, Paulo Roberto Iotti. Constitucionalidade do Projeto de Lei $\mathbf{n}^{0}$ 5.003/2001: Uma Réplica a Paulo Medeiros Krause. Disponível em: <https://jus.com.br/artigos/10248/constitucionalidade-do-projeto-de-lei-n-5-003-2001>. Acesso em 17 de maio de 2018.

\section{VIOLATION OF HUMAM RIGHTS THROUGH DISCRIMINATION: AS OVERVIEW OF VIOLENCE FROM INTERSECTIONALITY}

\section{ABSTRACT}


The present work presents in a brief way the scenario of the violence experienced by sexual minorities. The relationships of power and subalternation experienced by sexual minorities through an intersectional perspective are exposed in a reflexive way, showing how other social markers of marginalization - not only sexual and gender - can interfere in these relations of power and in the degree of violence experienced by individuals. In addition, the article reflects on the laws and legal mechanisms that should promote protection for this group, but are not applied in the factual reality of people, either by political choices or because they can not reach individuals due to their homogenizing character. The article concludes by arguing how an intersectional reading can be beneficial in exposing deeper relationships of domination.

Keywords: Intersectionality. Sexual and gender violence. Human rights. Social bookmarks. 